\title{
Measuring and Sustaining the Impact of Less Commonly Taught Language Collections in a Research Library
}

\author{
Joe Lenkart, Thomas H. Teper, Mara Thacker, and \\ Steven W. Witt
}

To evaluate the current state of resource sharing and cooperative collection development, this paper examines the relationship between less commonly taught language collections (LCTL) and ILL services. The study examined multiple years of the University of Illinois at UrbanaChampaign's resource-sharing data. This paper provides a historical narrative for the multilingual collections, collection development strategies, reference services, and outreach initiatives that reinforce and strengthen scholarly communication and resource sharing among academic libraries. The paper concludes by examining the feasibility of aggregating, or concentrating, collections of difficult-to-acquire, low-use materials at institutions that can provide service at a regional and/or national level.

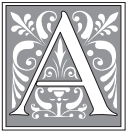

$\mathrm{t}$ the start of the twentieth century, the University of Illinois' President, Edmund James, set forth a vision of a million-volume library that would attract pre-eminent scholars to the middle of the American prairie. ${ }^{1}$ This was an ambitious aspiration for a library that numbered only 1,039 volumes when the University of Illinois at Urbana-Champaign (UIUC) opened in 1868. Approximately 100 years after James' 1912 call, the library's collection numbers over 13 million volumes and tens of millions of other items, and its service programs contribute toward the university's standing as a vibrant and robust global institution. As of 2013, the university library supports five nationally funded resource centers focused on international and area studies that work with more than 800 affiliated faculty members, runs the Title VIII-funded Slavic Reference Service (SRS), and houses the Mortenson Center for International Library Programs. The library's contributions toward cooperative collection development and resource-sharing partnerships afford researchers from around the world unprecedented access to its multilingual collections and services. By acquiring scarcely held materials in the vernacular languages of Eurasia, Africa, Latin America, the Middle East, East and South Asia and making a generous commitment

Joe Lenkart is International Reference Librarian, Thomas H. Teper is Associate University Librarian for Collections and Technical Services, Mara Thacker is South Asian Studies Librarian, and Steven W. Witt is Head of the International and Area Studies Library in the Main Library at the University of Illinois at Urbana-Champaign; e-mail: lenkart@illinois.edu, tteper@illinois.edu,mthacker@illinois.edu, swwitt@ illinois.edu. The authors would like to acknowledge the assistance of Cherie Weible and Esra Coskun in the preparation of this manuscript. (C) 2015 Joe Lenkart, Thomas H. Teper, Mara Thacker, and Steven W. Witt, Attribution-NonCommercial (http://creativecommons.org/licenses/by-nc/3.0/) CC BY-NC. 
to share these resources, the university library has become a reliable destination for scholarly inquiry. By building strong collection development activities in Slavic and East European languages and joining them with an outward-facing service component such as the SRS and Summer Research Laboratory, which has been in service for the last 41 years, the university library developed a reputation as a national resource for facilitating scholarly access to Slavic and East European materials located within its own collections and for providing assistance for those seeking access to the holdings of other institutions in the United States and abroad.

\section{Problem Statement}

To draw conclusions about the current state of resource sharing and the role that cooperative collection development could play in serving the community of scholars requiring access to resources published in Less Commonly Taught Languages (LCTL), the authors evaluated multiple years of ILL transactions, focusing on UIUC's fulfillment of requests for non-English collections. The dataset underlying the authors' quantitative analysis covered five years of UIUC's lending for those materials identifiable as being published in languages considered less commonly taught in North America (as identified by the National Council of Less Commonly Taught Languages: http://www. ncolctl.org/). By analyzing these data, the authors sought to draw conclusions about how intensively collections of area studies materials housed at one institution serve broader user communities, to what extent such collections and associated services benefitted individuals beyond the community of research universities, and whether the borrowing of specialized materials from one university was limited to a particular geographic area.

\section{Literature Review}

Research on the use of vernacular language materials is fairly limited when viewed within the context of a defined network of borrowing institutions and the set parameters of this study. Although there is a long bibliography of studies examining interlibrary loan operations and extensive research on the role of area studies collections, limited research exists on the role of ILL in serving foreign language collections.

In recent years, Edward T. O'Neill and Julie A. Gammon's paper, "Building Collections Cooperatively: Analysis of Collection Use in the OhioLINK Library Consortium," demonstrated that statewide networks of libraries often overacquired many titles necessary to serve their user populations. While multiple holdings benefitted users in some cases, usage indicated that significant bodies of material did not require duplicate holdings to serve a network as broad as the OhioLINK membership. ${ }^{2}$ When viewed from the perspective of a single institution, the use of ILL data to shape collection development decisions is problematic. For example, Andrew Leykam's 2008 study, "Exploring Interlibrary Loan Usage Patterns and Liaison Activities: The Experience at a U.S. University" cautions against using ILL statistics as a basis for collection development decisions, as these requests may reflect the interests of individual users and not broader institutional needs. ${ }^{3}$ On the network level, however, the benefits of using usage patterns to develop the evidence needed to define appropriate levels of collecting for less commonly used items has not been explored. Wiley, Chrzastowski, and Baker's 2011 examination of domestically produced monographs in Illinois' I-Share network from UIUC underscored many of O'Neill and Gammon's results. ${ }^{4}$ These studies point to something that many librarians long suspected, namely that the long tail of our holdings - those items infrequently used and not needed for regular on-site reference-type consultation-could effectively serve broader populations of scholars if resource-sharing networks exist to facilitate access and usage within defined geographic areas. 


\section{The Development of a National Collection for International and Area Studies}

Since the early twentieth century, the development of collections to support area studies sought to transcend the idea that collection development needed to build collections only to serve local needs. As early as 1918, the Carnegie Endowment for International Peace invested in what became the international and area studies in an attempt to foster mutual understanding and international peace. This was accomplished through support for new academic programs, faculty lines, research centers, and library collections, all of which were intended to raise the consciousness of individuals both in the United States and abroad about the cultures, languages, and political systems of other countries. ${ }^{5}$ From the 1930 s to the 1950s, foundations provided the principal funding source for non-Western research programs, with significant support coming from the Carnegie, Rockefeller, and Ford foundations. ${ }^{6}$

After World War II, collections in international and area studies across the United States began developing in a more coordinated fashion, in part as a result of the Carnegie-supported Farmington Plan, a program that sought both to establish a national program to collect and make accessible materials from abroad and to fill gaps in collections created by disruptions in the book trade resulting from the war. ${ }^{7}$ Although the plan initially focused on Western European materials, it expanded to include publications from throughout the world. The Farmington Plan contributed to notions of a national collection of foreign language materials by obligating libraries to allocate funds toward acquisitions from chosen regions and subject areas, and requiring that they make the books acquired available nationally. ${ }^{8}$ UIUC participated in the Farmington Plan, just as it had in earlier national programs to develop area studies. By 1951, UIUC acquired more books through the Farmington Plan than any other library in the United States. ${ }^{9}$

By the late 1950s, the Cold War-and the escalation of fear that accompanied the Soviet launch of Sputnik in 1957-provided further momentum toward federal support of foreign language programs across the United States. Developed as a national security measure, the National Defense Education Act (NDEA) of 1958 created area studies centers on research university campuses and prompted the further acquisition of foreign language materials. In the early years of the NDEA, library expenditures accounted for $12 \%-15 \%$ of the legislated funding. An initial report on the NDEA touted funding for non-Western language collections as an important stimulus "in increasing the Nation's library resources in fields where research libraries are rare."10 In the 1963-1964 grant cycle, NDEA provided $\$ 135,920$ in support for collections and $\$ 171,426$ for library personnel, averaging to over $\$ 5,000$ in support for each NDEA center. ${ }^{11}$ Based on U.S. Bureau of Labor Statistics estimates, this would equal roughly $\$ 37,592$ in 2013 . The 1960 NDEA funding included resources to directly support UIUC's efforts to establish the library's Slavic collections. By 1965, this federal support helped establish the Far Eastern and South and West Asian Library and collections in Latin American and Caribbean Studies. In 1969, the program initiated UIUC's hiring of an African studies librarian.

In 1958, Congress passed Public Law 83-480 (P.L. 480), which authorized the Library of Congress to acquire materials on behalf of other libraries and research centers in the United States. Focused on acquiring research materials in non-Western languages, the P.L. 480 program provided further incentives for national cooperative collecting efforts. Beginning with a South Asian focus on India and Pakistan, the program expanded to include publications from South East Asia, the Middle East, and Central Europe. Forty-six U.S. research libraries, including Illinois, participated in this program, which contributed 1,699,029 volumes to the "national" foreign language collection through $1971 .{ }^{12}$ In addition to acquisitions, the program provided another model for cooperative library services by concentrating and sharing cataloging expertise with the Library of Congress. 
By 1965, the focus of the NDEA shifted from being one of defense education to being an educational initiative, with funding moving under the authority of the U.S. Department of Education through inclusion under Title VI, Part A, §602 of the Higher Education Act of 1965. Evaluation of the success of the Title VI National Resource Center program emphasized libraries as critical components of a national program in area studies. At this time, emphasis on collections also shifted to include services to actively promote national access to the expertise concentrated in research libraries. Combined Title VI and Doris Duke Foundation funding in 1973 provided the seed for UIUC's Summer Research Lab for Slavic scholars to conduct research at UIUC's library and work with its subject specialists. In 1976, the library initiated the SRS' development with support from the campus's Russian center and funding provided by the U.S. Department of State's Title VIII program. Aimed at funding research and language training for the study of the Soviet Union, Title VIII helped to develop a national reference service to support access to Slavic language materials among academics and researchers in the public and private sectors.

A 1984 assessment of the Title VI program included a full chapter that focused on library and information resources. One of the main areas of emphasis in this report was resource sharing and cooperation, with emphasis on the inadequacy of systems for sharing resources between academic and government institutions. Of the seven recommendations for libraries that support language and area studies, one related directly to the notion of developing a national repository of foreign language materials coordinated and made available through academic libraries. The recommendation called for the "development of a plan and a strategy for reducing collection redundancy and increasing inter-collection sharing of resources." ${ }^{13}$

Today, foundations and the federal government continue developing and strengthening collections in non-Western languages that are less frequently taught and studied on U.S. campuses. Now referred to as Less Commonly Taught Languages (LCTL), these consist of all languages with the exception of English, French, German, Italian, and Spanish. The Title VI program remains one of the only federal programs that provide funds to supplement acquisitions at individual institutions, bolstering the libraries at the 125 National Resource Centers (NRCs) that focus on regional and international studies. Through their support of these NRCs, research libraries developed a vast national network of collections and services to support academic, corporate, and government enterprises. Academic libraries that serve American colleges and universities became a central component of the national strategy to build and sustain the expertise in languages and area studies necessary to educate those individuals who will serve both the public and private sectors of an increasingly global environment.

Although the development of area studies collections is over 100 years old, little research or evidence exists about the national impact of this network of the foreign language collections that comprise a collective resource for educational institutions, corporations, and intelligence services. As noted in the 1984 Lambert report and emphasized in programs such as the Farmington Plan, the power of these often unique collections resides in national availability and accessibility through research libraries. One of the measures for the success of these programs and their impact nationally is the level at which LCTL materials are shared across institutions and institutional types.

Absent such research, libraries and academic institutions draw upon volume counts to justify the century of support received through foundations and the federal government. As federal budgets are trimmed and foundations focus less on academic disciplines and more on problem solving, libraries must develop new tools to measure their contribution to the national goals of these collections. The history of these collections makes one thing clear: their funding and goals are interconnected with 
broader national needs. It is essential to articulate how collections such as these serve the broader community.

\section{The Impact of One Research Collection: The Use of LCTL Materials at Illinois by Non-Illinois Users}

In this study, the authors examined the regional distribution for outgoing materials, the types of institutions that borrowed the materials, and which languages were the most frequently borrowed. Assessment of the impact of the collection is focused on the access provided to LCTL collections and the distribution of these specialized materials among institutions nationally. To achieve this, the authors addressed the following five questions:

1. Is the impact of these collections constrained by geographic proximity and/or consortial arrangements?

2. Does a deeper, centrally held collection of Less Commonly Taught Language materials serve the broad academic community?

3. Beyond the academic community, who else benefits from LCTL materials collections? How does this compare with academic usage?

4. Can the breadth of usage justify longstanding institutional and governmental financial commitments?

5. How does a robust service component affect the ILL lending of LCTL materials?

Data needed to answer many of the research questions for this project resided in reports made available by UIUC's Interlibrary Loan department. Information about the library's ILL lending transactions from 2007-2011 were supplied after being redacted to obscure information that could be used to identify individual borrowers. The fields included in the data are shown in table 1.

\begin{tabular}{|c|c|c|c|}
\hline \multicolumn{4}{|c|}{ TABLE 1 } \\
Record Fields \\
\hline Borrower Symbol & Borrower Full Name & Borrow State & ILL Record Number \\
\hline Title & Author & Date 1 & Imprint \\
\hline OCLC Number & $\begin{array}{c}\text { Call Number } \\
\text { Congress/Other }\end{array}$ & Call Number/Dewey & $\begin{array}{c}\text { Call Number } \\
\text { Medicine }\end{array}$ \\
\hline Language & CTL/LCTL/NA & Region & ISBN \\
\hline ISSN & Maximum Cost & Lending Charges & Article (Citation) \\
\hline Date (Citation) & Numbers (Citation) & Pages (Citation) & Volume (Citation) \\
\hline Dissertation Notes & Photocopy Flag & Received Before & Received This \\
& This Month & Month \\
\hline Series Notes & $\begin{array}{c}\text { Lender Received } \\
\text { Date }\end{array}$ & $\begin{array}{c}\text { Lender Filled Date } \\
\text { Lender Unfilled } \\
\text { Date }\end{array}$ \\
\hline Library Type & $\begin{array}{c}\text { Borrow Completed } \\
\text { Date }\end{array}$ & & \\
\hline
\end{tabular}

Upon receipt of the monthly reports, the authors combined the monthly files by year for analysis. At the low end, the data for 2011 contained 34,803 records; at the high end, the data from 2007 contained 45,319 records.

Next, the researchers isolated transactions in which UIUC served as the lender of materials in Less Commonly Taught Languages (LCTLs) from those transactions in 
which UIUC lent materials identified as being authored in the more commonly taught languages of English, French, German, Italian, and Spanish. The authors then grouped the LCTLs into the following geographical categories: African, East Asian, Latin American (other than Spanish and Portuguese), Middle Eastern, Russian/East European/Central Asian/Eurasian, South Asian, Southeast Asian, and Western European. ${ }^{14}$ In addition, the authors created a separate category for Portuguese, as a significant number of UIUC's Portuguese language materials are Brazilian rather than Portuguese.

The authors further organized the data by dividing the United States into the four regions prescribed by the U.S. Census Bureau: the Southern United States, Northeastern United States, Western United States, and Midwestern United States. This facilitated analyzing the geographic distribution of outgoing materials and helped the authors identify significant borrowing trends.

\section{Biases}

Although the authors endeavored to include as much of the collection as possible within the sample, the language-based focus of the assessment introduced some biases:

- The researchers omitted those transactions in which the language was unlisted or unknown. Reconciling this would require manual evaluation of thousands of records and, likely, thousands of individual items.

- The data excluded those materials coded as being multilingual due to the difficulty in individually identifying the dominant language in the text.

- As a language-based study that makes some attempt to cross-walk into the geographic regions regularly found within area studies fields, the place of publication was omitted, meaning, for example, that Russian language publications from the United States may remain within the sample while English-language publications from the Indian Subcontinent will not be represented.

\section{Results}

Is the impact of these collections constrained by geographic proximity and/or consortial arrangements?

The authors expected that lending would be skewed toward a higher volume of outgoing materials being sent to institutions in the Midwestern United States. This was expected because of the library's reciprocal borrowing agreements with Illinois' statewide I-Share network and the Committee on Institutional Cooperation (CIC), an academic consortium of universities primarily located in the Midwest, and because of a tendency for ILL departments to favor lending and borrowing with geographically close institutions to reduce shipping costs and turnaround time when there is a choice. The data supported this supposition and showed that, between 2007 and 2011, a little more than 50 percent of the total number of LCTL materials borrowed went to institutions within the Midwestern United States. Even when the researchers removed loans to other institutions in Illinois to eliminate the in-state bias created by I-Share, institutions in the Midwest borrowed nearly 40 percent of the total number of LCTL materials. The next highest borrower of LCTL materials was the Southern United States, which accounted for nearly 24 percent of the LCTL items. The Northeastern United States borrowed nearly 20 percent, and the Western United States borrowed 17 percent of the LCTL language materials.

Does a deeper, centrally held collection of Less Commonly Taught Language materials serve the broader academic community?

UIUC possesses one of the largest and richest collections of foreign language materials at a North American academic institution. By 2013, UIUC's collection included materials in over 400 different languages, with more than 125 languages having 100 or more 


\begin{tabular}{|l|c|c|c|c|c|}
\hline \multicolumn{7}{|c|}{ TABLE 2 } \\
\hline Region & $\begin{array}{c}\text { LCTL } \\
\text { Lending }\end{array}$ & $\begin{array}{c}\text { Total } \\
\text { Lending }\end{array}$ & $\begin{array}{c}\text { \% of } \\
\text { Regional } \\
\text { Borrowing } \\
\text { of LCTL } \\
\text { Materials }\end{array}$ & $\begin{array}{c}\text { Regional } \\
\% \text { of LCTL } \\
\text { Borrowing }\end{array}$ & $\begin{array}{c}\text { \% of Total } \\
\text { Borrowing } \\
\text { to Region }\end{array}$ \\
\hline Southern US & 3,760 & 23,515 & $15.99 \%$ & $19.41 \%$ & $12.43 \%$ \\
\hline Northeastern US & 3,063 & 20,754 & $14.76 \%$ & $15.81 \%$ & $10.97 \%$ \\
\hline Western US & 2,750 & 15,490 & $17.75 \%$ & $14.19 \%$ & $8.19 \%$ \\
\hline Midwestern US & 9,801 & 129,387 & $7.57 \%$ & $50.59 \%$ & $68.41 \%$ \\
\hline Total & 19,374 & 189,146 & & & \\
\hline
\end{tabular}

\begin{tabular}{|l|c|c|c|c|c|}
\hline \multicolumn{7}{|c|}{ TABLE 3 } \\
\hline & $\begin{array}{c}\text { LCTL } \\
\text { Lending }\end{array}$ & $\begin{array}{c}\text { Total } \\
\text { Lending }\end{array}$ & $\begin{array}{c}\text { \% of } \\
\text { Regional } \\
\text { Borrowing } \\
\text { of LCTL } \\
\text { Materials }\end{array}$ & $\begin{array}{c}\text { Regional } \\
\% \text { LCTL } \\
\text { Borrowing }\end{array}$ & $\begin{array}{c}\text { \% of Total } \\
\text { Borrowing } \\
\text { to Region }\end{array}$ \\
\hline Southern US & 3,760 & 23,515 & $15.99 \%$ & $23.88 \%$ & $19.75 \%$ \\
\hline Northeastern US & 3,063 & 20,754 & $14.76 \%$ & $19.45 \%$ & $17.43 \%$ \\
\hline Western US & 2,750 & 15,490 & $17.75 \%$ & $17.46 \%$ & $13.01 \%$ \\
\hline Midwestern US & 6,174 & 59,296 & $10.41 \%$ & $39.21 \%$ & $49.81 \%$ \\
\hline Total & 15,747 & 119,055 & & & \\
\hline
\end{tabular}

cataloged items. The top most collected LCTL is Russian, which comprises over 247,000 volumes and is the fourth most heavily collected language exclusive of English. The next largest LCTL collections are Chinese, Portuguese, Arabic, Japanese, Ukrainian, Hindi, and Polish. The library holds more than 30,000 volumes in each of these languages. All other languages represented in UIUC's collection number fewer than 30,000 volumes.

The size of each language collection often corresponds with the lending volume of materials in that language. For example, Russian language materials accounted for 3 percent of UIUC's overall lending and nearly a third of the LCTL lending transactions. Indeed, LCTL materials from the Slavic, East European, and Eurasian collection (inclusive of those materials from the former Soviet states and those that fell behind the Iron Curtain) comprised half of the overall LCTL lending and 5 percent of UIUC's total ILL lending. This trend held steady for all five years analyzed.

After the Slavic collection, the East Asian collection saw the next heaviest usage, accounting for about 3 percent of overall lending and almost a third of the LCTL lending. Chinese and Japanese each accounted for about half of the East Asian lending. With the addition of Middle Eastern and Portuguese resources to the aforementioned Slavic, Chinese, and Japanese collections, the authors defined the only LCTL materials in which overall lending for the categories reached the level of a full percent. ${ }^{15}$

While none of the lending for other LCTL language materials account for a whole percentage of overall lending, many materials in other languages including Hindi, Tamil, Korean, Swahili, and more were lent out to institutions across the United States. 


\begin{tabular}{|l|c|c|c|c|}
\hline \multicolumn{5}{|c|}{ TABLE 4 } \\
\hline Region* Collections by Region, Collection Size, and ILL Lending \\
\hline African Languages & Titles & Percent & Lending & Percent \\
\hline East Asian & 5,840 & $0.08 \%$ & 23 & $0.07 \%$ \\
\hline South Asian & 182,256 & $2.44 \%$ & 894 & $2.58 \%$ \\
\hline Middle Eastern & 99,798 & $1.34 \%$ & 70 & $0.20 \%$ \\
\hline Slavic, East Europe, Eurasian & 57,761 & $0.77 \%$ & 173 & $0.50 \%$ \\
\hline $\begin{array}{l}\text { *Regional collection totals reflect titles and exclude volumes and materials published in non-LCTL } \\
\text { languages. Latin America and the Caribbean were excluded because of the inability to disaggregate } \\
\text { within the dataset European and Latin American imprints for Portuguese titles. Percentages are } \\
\text { derived from the Library's title count of 7.4 million at the end of 2011. }\end{array}$ \\
\hline
\end{tabular}

Combined, the borrowing of major academic research libraries and smaller academic libraries from UIUC equals 86.09 percent of total lending and 91.61 percent of LCTL lending. This demonstrates that both our more robust collections and our smaller holdings are heavily borrowed to support research libraries across the nation.

Beyond the academic community, who else benefits from LCTL materials collections? How does this compare with academic usage?

The rate of borrowing of LCTL materials from this research library's collection suggests multiple benefits imparted to nonacademic institutions through access to LCTL collections. The primary benefit is access to materials that would not otherwise be available or require too much time and too many resources to acquire, organize, and make accessible in time to support immediate research needs. Nearly 8.39 percent of UIUC's LCTL lending goes to nonacademic institutions, supporting the research needs of individuals that are borrowing through their libraries in the federal, state, and municipal governments; public libraries; corporate libraries; and junior, community, or technical colleges, among others.

While the aggregated volume of LCTL borrowing by nonacademic users was relatively small, the impact was high. For example, while federal government libraries borrowed only a little more than 300 items from UIUC in 2011, more than 10 percent were LCTL materials. This proportion was relatively stable over the five year period from 2007 to 2011, resulting in an average of 8.2 percent of the materials borrowed by the federal government being LCTL materials, indicating that the government receives a return on its investment in Title VI funding.

Borrowers classified as state and municipal government libraries also benefit from using the LCTL collections at UIUC; interestingly, the usage increased significantly within the period studied. While 2007 saw state and municipal government libraries borrowing LCTL materials only at a rate of 3.5 percent of the total borrowed, by 2010 17.1 percent of the materials borrowed by these agencies were LCTL materials, reaching 18.6 percent in 2011.

Other types of institutions borrowing a relatively high proportion of LCTL materials included those defined as associations and foundations, which, like the state and municipal government libraries, showed an increase in the proportion of LCTL materials borrowed in recent years. While in 2005 only 5 percent of materials borrowed were LCTL materials, by 201115 percent of the materials lent to associations and foundations were LCTLs. This is despite an overall decrease in the amount of total lending. (Please see table 5 for the average LCTL lending by institution type from 2007 to 2011.) 


\begin{tabular}{|l|c|c|c|c|c|c|}
\hline \multicolumn{7}{|c|}{ TABLE 5 } \\
\hline Library Type & CTL & LCTL & $\begin{array}{c}\text { Total } \\
\text { Lending }\end{array}$ & $\begin{array}{c}\% \\
\text { Borrowed } \\
\text { LCTL }\end{array}$ & $\begin{array}{c}\% \text { of Total } \\
\text { LCTL } \\
\text { Loaned }\end{array}$ & $\begin{array}{c}\% \text { of Total } \\
\text { Loaned }\end{array}$ \\
\hline Academic & 94,952 & 11,496 & 106,448 & $10.80 \%$ & $57.81 \%$ & $56.86 \%$ \\
\hline $\begin{array}{l}\text { Art Music } \\
\text { History }\end{array}$ & 1 & 0 & 1 & $0.00 \%$ & $0.00 \%$ & $0.00 \%$ \\
\hline $\begin{array}{l}\text { Association/ } \\
\text { Foundation }\end{array}$ & 590 & 50 & 640 & $7.81 \%$ & $0.25 \%$ & $0.34 \%$ \\
\hline Corporate & 2,511 & 161 & 2,672 & $6.03 \%$ & $0.81 \%$ & $1.43 \%$ \\
\hline Federal/National & 2,246 & 201 & 2,447 & $8.21 \%$ & $1.01 \%$ & $1.31 \%$ \\
\hline $\begin{array}{l}\text { Junior, } \\
\text { Community, } \\
\text { Tech College }\end{array}$ & 1,457 & 84 & 1,541 & $5.45 \%$ & $0.42 \%$ & $0.82 \%$ \\
\hline Law Library & 1,264 & 52 & 1,316 & $3.95 \%$ & $0.26 \%$ & $0.70 \%$ \\
\hline $\begin{array}{l}\text { Major Academic } \\
\text { Research }\end{array}$ & 47,996 & 6,722 & 54,718 & $12.28 \%$ & $33.80 \%$ & $29.23 \%$ \\
\hline Medical & 243 & 3 & 246 & $1.22 \%$ & $0.02 \%$ & $0.13 \%$ \\
\hline Other & 394 & 34 & 428 & $7.94 \%$ & $0.17 \%$ & $0.23 \%$ \\
\hline Public & 13,564 & 918 & 14,482 & $6.34 \%$ & $4.62 \%$ & $7.74 \%$ \\
\hline $\begin{array}{l}\text { Schools below } \\
\text { College Level }\end{array}$ & 439 & 12 & 451 & $2.66 \%$ & $0.06 \%$ & $0.24 \%$ \\
\hline State Library & 503 & 37 & 540 & $6.85 \%$ & $0.19 \%$ & $0.29 \%$ \\
\hline $\begin{array}{l}\text { State or } \\
\text { Municipal } \\
\text { Government }\end{array}$ & 582 & 54 & 636 & $8.49 \%$ & $0.27 \%$ & $0.34 \%$ \\
\hline Theological & 570 & 61 & 631 & $9.67 \%$ & $0.31 \%$ & $0.34 \%$ \\
\hline Total & 167,312 & 19,885 & 187,197 & & $100.00 \%$ & $100.00 \%$ \\
\hline
\end{tabular}

Can the breadth of usage justify the longstanding institutional and governmental financial commitments?

The data show that various types of institutions, especially those in the academic community and those falling within various levels of government, use LCTL materials regularly. This shows a direct benefit and return on institutional and governmental financial commitments to these collections. Does the benefit fully offset the costs of acquisition? An answer to that question would surely omit some aspects of the cost for acquiring and maintaining the materials over time. Moreover, such an attempt to quantify the cost ignores the even more difficult problem of quantifying the opportunity cost of not acquiring a resource. What is clear, however, is the correspondence between the size of a particular area collection and the volume of borrowing from that collection. As table 4 displays, nearly 50 percent of LCTL lending coincides with Slavic collections, the strongest among the area studies holdings in UIUC's collection. The potential for single aggregations of holdings or strict agreements between partners to reduce duplication between institutions and thereby increase overall collecting depth indicates that such moves would constitute wise investments, as reduced duplication 
of lesser-used materials coupled with firm resource-sharing commitments hold the potential to serve broader scholarly communities.

How does a robust service component affect ILL lending of LCTL materials?

LCTL materials in Slavic, East European, and Eurasian languages account for nearly half of UIUC's total LCTL lending and 5 percent of UIUC's overall lending. While Russian is the most borrowed language from that collection, materials in Czech, Croatian, Romanian, Ukrainian, and Polish also saw significant usage. When the percentage of the collection and percentage of lending are compared, lending of Slavic materials maps closely. With the exception of South Asian materials, however, other LCTL collections and lending patterns also coincide (see table 4). Therefore, the data are ambiguous regarding the impact of services on ILL lending of LCTL materials.

For example, it is difficult to assess the contributions of service to the borrowing rate of the Slavic, East European, and Eurasian collection, which is the largest LCTL grouping represented at UIUC and possesses well-developed and outward-facing service component. When viewing reference statistics, service is clearly a factor. During the five-year period analyzed in this study, the SRS fielded 17,129 reference transactions. In 2011, 2,491 transactions came from outside the UIUC community, and 1,459 inquiries were directly related to ILL and document delivery (DD) requests being from on or off campus.

\section{Observations and Conclusions}

Over the years, many research libraries experimented with and implemented successful cooperative collection development and management programs. Some focused on developing agreements between relatively limited numbers of research institutions that are often geographically close to one another. Examples can be found in the Research Triangle libraries, bilateral collection agreements between institutions such as Stanford and Berkeley, and, more recently, the 2CUL partnership between Cornell and Columbia. Other groups, such as the Committee on South Asian Libraries and Documentation (CONSALD), developed agreements among the community of subject specialists serving a particular area to ensure the least redundancy and broadest coverage among North American research libraries for acquisitions from a given region. These models point toward options for other communities in the area studies, but none of them eliminate the need for some level of local expertise. Even some of the more aggressive efforts at sharing services - such as those found in the TRLN or 2CUL partnerships-do not completely eliminate the need for a local presence-even if it is shared.

Contrasted with the federated model of the CONSALD membership or other limited bi- or tri-lateral institutional partnerships focused on collection development, one can view the extensive cooperative that has become today's Center for Research Libraries (CRL) as a model with strengths to emulate. In this model, a robust investment fostered a collection of predominantly lesser-used materials that serves the scholarly community through a combination of on-site expertise and community engagement. If we look beyond CRL's large physical plant and independent member organization, we see a strong collection and a service layer that are viewed as enhancements to the local holdings and expertise of individual members.

From the standpoint of serving a community of research libraries, the data analyzed in this study reinforces the notion that aggregation is advantageous. Moreover, the model under which the CRL developed over half a century ago indicates that funding hubs of collecting excellence has the potential to serve the national interest. Whether funded locally or collectively, evidence indicates that deeper collections held in fewer locations can result in less collective redundancy of holdings, providing the community of scholars with access to a deeper body of scholarly material while maximizing our collective 
investment. This is the entire model underlying the cooperative agreement among the CONSALD members, and it benefits scholars at their member institutions and beyond by providing the entire community of users access to deeper collections across the nation.

The advantage in building deeper collections benefits not just the academic community. As the authors demonstrated, a disproportionate proportion of LCTL lending from UIUC serves agencies of local, state, and federal government; corporate borrowers; community colleges; and other users. As a significant number of LCTL materials have been demonstrated to be both less commonly held and less frequently used, one could presume that there is less need for redundancy in our holdings. Consequently, aggregating holdings of lesser-used materials to reduce redundancy across institutions - or at the very least ensuring less redundancy through cooperative collection development agreements - should benefit our users and serve the national interest by permitting deeper collecting in particular subject areas. The community of research libraries believes that cooperative collection development programs benefit our users. The decades-long body of literature about such activities attests to the ongoing perception of value in such efforts, and enhancements in communications, lending programs, and resource sharing should serve to make them more beneficial to the community at large in the coming years. However, the ability of scholars in North America to take maximum advantage of these collections is stymied at many institutions in which there is neither local expertise nor a history of collecting. As the authors have demonstrated through their analysis of the borrowing from UIUC's collections of LCTL materials, students and scholars at institutions across the nation benefit from aggregations of collections that serve communities far beyond the immediate geographic area. When coupled with the development of outward-facing service programs, such as specialized reference services that enhance ILL transactions and that facilitate discovery, the benefit of such aggregation is magnified. While the high percentage of Slavic materials within UIUC's LCTL lending numbers likely results from the size of the institution's Slavic collections, the evidence from our own service programs indicate that a large number of the service questions received by the Slavic Reference Service result in additional ILL/DD requests being received from non-UIUC patrons who have discovered unknown items within our collection. This suggests that there may also be benefits to aggregating services in coordination with collections.

At the UIUC, the university library developed a robust, outward-facing service program in the SRS. Since its founding in 1976, the SRS has served patrons regardless of academic status or institutional affiliation. ${ }^{16}$ The foundation for this model rests on the partnership formed between information professionals in ILL and the SRS. This partnership assists scholars with citation verification and provides in-depth bibliographic assistance with vernacular language materials. Through this partnership and outward-facing service model, the SRS facilitates the lending of resources from UIUC's collection, the provisioning of content from abroad, and, in some cases, the discovery of resources for patrons at their own institutions. This service does not replace the need for local expertise at tier-one research libraries - it enhances it. Further, for the many students and scholars at smaller institutions and agencies in the public sector, the SRS facilitates research by providing greater access to ILL/DD services.

An outward-facing service component also supports user interaction with discovery systems, transliteration, and display issues that continue to erect barriers for those seeking to access LCTL collections. Often bad citations or poor translations result in unfulfilled ILL requests and inhibit access. Working through a service such as the SRS, however, patrons and ILL professionals navigate gaps in integrated systems, transliteration, and cataloging, filling requests, and successfully connecting users with area studies collections from around the world. 
Clearly such an aggregated service works to support ILL and contributes to the high number of successful requests for Slavic, East European, and Eurasian materials. If this relationship between collections, specialized reference, and ILL services across institutions were to be nurtured and expanded to other areas, the proven track record of the SRS in providing reliable service to Russian, East European, and Eurasian Studies scholars could serve as a model for developing and maintaining similar services for other LCTL collections. Further research that provides a more qualitative perspective on the impact of an outward-facing service model such as the SRS is needed to more fully understand the interaction between vernacular reference services and enhanced access to LCTL collections nationally.

As research libraries continue collecting fewer copies of LCTL materials, the community should consider both the need to make systematic decisions about holdings and the discovery implications of such decisions. This will only become more imperative as our institutions continue digitizing backfiles of print monographs, enhancing the discovery of many items that are not yet in the public domain. It is clear that limited numbers of copies can serve a broad community of scholars; however, discovering and eventually accessing a resource across the network will be enhanced by the development of outward-facing services that are intended to serve the broader community.

\section{Notes}

1. Twenty-sixth Report of the Board of Trustees of the University of Illinois (Springfield, Ill.: Illinois State Journal Co., State Printers, 1912), 595-97.

2. Edward T. O'Neill and Julia A. Gammon, "Building Collections Cooperatively: Analysis of Collection Use in the OhioLINK Library Consortium," in Pushing the Edge: Explore, Engage, Extend: Proceedings of the Fourteenth National Conference of the Association of College and Research Libraries March 12-15, 2009, Seattle, Washington, 36-45.

3. Andrew Leykam, "Exploring Interlibrary Loan Usage Patterns and Liaison Activities: The Experience at a US University," Interlending \& Document Supply 36, no. 4 (2008): 218-24.

4. Lynn Wiley, Tina E. Chrzastowski, and Stephanie Baker, "A Domestic Monograph Collection Assessment in Illinois Academic Libraries: What Are We Buying and How Is It Used?" Interlending \& Document Supply 39, no. 4 (2011): 167-75.

5. Carnegie Endowment for International Peace, Annual Report (New York: Carnegie Endowment for International Peace, 1918), 38.

6. Joseph Axelrod, Donald Nevius Bigelow, and American Council on Education, Resources for Language and Area Studies (Washington, D.C.: American Council on Education, 1962).

7. Ralph D. Wagner, A History of the Farmington Plan (New York: Scarecrow, 2002). $156-65$.

8. Edwin E. Williams, "Some Questions on Three Cooperative Projects," Library Trends (1952):

9. Ibid.

10. Donald N. Bigelow and Lyman H. Legters, NDEA Language and Area Centers: A Report on the First 5 Years. Bulletin, No. 41, OE-56016 (Washington, D.C.: Office of Education, U.S. Department of Health, Education, and Welfare, 1964), 46.

11. Ibid., 127.

12. Tahany Said El-Erian, "The Public Law 480 Program in American Libraries" (PhD diss., Columbia University, 1972).

13. Richard D. Lambert, Beyond Growth: The Next Stage in Language and Area Studies (Washington, D.C.: Association of American Universities, April 1984), 258.

14. These geographical divisions were made to align with the divisions used by the United States Department of Education in the Title VI applications This crosswalk provides some means for communication with NRCs, but it is important to note that the analysis is all language based.

15. Portuguese was pulled as a separate category since it was not feasible to determine whether the materials being lent were from Portugal or Brazil.

16. Marianna Tax Choldin and Mary Stuart, "Resources for Cooperative Reference: The University of Illinois Slavic Reference Service as a Model," RQ 21, no. 1 (Fall 1981): 34-39. 